\title{
The Role of the Neutral and Cationic Gelators from (1S,2S)-(-)-Diphenylethylenediamine for the Preparation of Silica Nano Tubes
}

\author{
Myung Ho Hyun, ${ }^{+}$Min Seob Shin, ${ }^{,+}$Tae Kyu Kim, ${ }^{+*}$ Ok-Sang Jung, ${ }^{\dagger}$ Jong Pil Kim, ${ }^{\ddagger}$ Hyun Jin Kim, \\ Euh Duck Jeong, ${ }^{, *}$ and Jong Sung Jin ${ }^{\ddagger}, *$ \\ "Department of Chemistry and Chemistry Institute for Functional Materials, Pusan National University, \\ Busan 609-735, Korea \\ "Ihgh-Technology Components \& Materials Research Center \& Busan Center. Korea Basic Science Institute (KBSI), \\ Busan 609-735. Korea. "E-mail: edjeongräkbsi.re.kr and jsin'äkhsi.re.kr \\ Received April 1, 2009. Accepted May 13,2009
}

Key Words: Silica nano tube, Gelators, (1S,2S)-(-)-Diphenylethylenediamine, Sol-gel transcription

Many scientists have recently been interested in the synthesis of helical silica nano tubes by using the self assemblies of chiral organic gelators as templates. As organic gelators, for example, sugar-integrated geloators ${ }^{\prime}$ or cholesterol-based gelators ${ }^{2}$ based on chiral compounds readily available from natural environments in an optically active form have been used for the preparation of silica nano tubes. Chiral trans1,2-cyclohexanediamine derivatives have also been known as excellent gelators that can harden a wide variety of organic fluids. Traths-(IR.2R)- or trans-(|S,2S)-1,2-di(undecylcarbonylamino)cyclohexane derivatives were reported to selfassemble into left-handed and right-handed helical organogel fibers, which are stabilized by inter molecular hydrogen-bonds through amide groups. ${ }^{3}$ The chiral self-assemblies based on these organic gelators have been successfully utilized as excellent templates for the sol-gel polycondensation of tetraethoxysilane (TEOS) into helical silica nano tubes. ${ }^{4}$ In order to transcribe the organogel structure into the silica structure, it was noticed that the cationic charge in the gelators is indispensable in the sol-gel polycondensation of TEOS, but the cationic gelators tend to lose the high gelation ability and rarely result in the helical structure. ${ }^{5}$ To overcome this dilemma, the mixture of the neutral and the cationic gelators have been utilized to form stable organogels supported by the helical fiber structure. ${ }^{5}$ However, it is not clear how the neutral and cationic gelators are integrated into the organogels while it is known that cationic charge is necessary for the sol-gel transcription in order to adsorb anionic silica particles onto the organogels.'

In order to explore how the neutral and cationic gelators are integrated into the organogels and to explore the role of the neutral and cationic gelators in forming silica tubes, in this study, we prepared two organic gelators $\mathbf{1}$ and $\mathbf{2}$ starting from

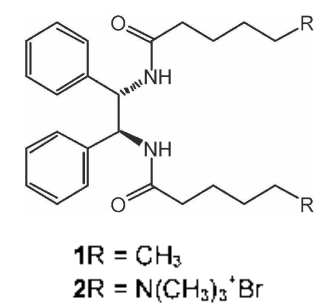

(1S.2S)-(-)-diphenylethylenediamine via the method utilized for the preparation of organic gelators from optically active trans-diaminocyclohexane. ${ }^{5}$ The structures of the two gelators prepared in this study were confirmed by the ${ }^{1} \mathrm{H}-,{ }^{13} \mathrm{C}-\mathrm{NMR}$, FT-IR spectral data and melting points.

Gelation abilities of neutral and cationic gelators ( 1 and 2 ) were tested in various solvents and the results are summarized in Table 1. Neutral gelator I can gelate ethanol, acetonitrile. n-butanol, tetrahydrofuran and ethyl acetate among eight solvents tested while cationic gelator $\mathbf{2}$ can partially gelate n-butanol only. However, when gelator 2 was mixed with gelator 1 , the mixed gelator $(\mathbf{1}, \mathbf{2}, 1: 1 \mathrm{wt} \%$ mixture $)$ was found to gelate ethanol, acetonitrile and n-butanol.

In order to see the morphological structures of organogels prepared in ethanol, the organogels prepared from gelator $\mathbf{I}$ and the mixed gelator were diluted with ethanol. The ethanol solution of gelator 2 was also diluted with ethanol. And then the partially dissolved organogels and the ethanol solution of gelator $\mathbf{2}$ were taken on the carbon grids five times. The carbon grids were frozen in liquid nitrogen and then were lyophilized. The resulting carbon grids were subjected to scanning electron microscopy (SEM). SEM results are shown in Figure I. In the case of neutral gelator I, rod-shaped structure is shown (Figure la), the thickness of the rods being in the rage of $70 \ldots$ $90 \mathrm{~nm}$. In the case of cationic gelator 2 , does not have any regular morphology (Figure lb) even though gelator $\mathbf{2}$ does not gelate ethanol under usual condition as shown Table 1.

Table 1. The gelation ability of gclator 1 . gelator 2 and the mixed gelator (1 । 2, 1:1 w0\% mixture)."

\begin{tabular}{|c|c|c|c|}
\hline Solvent & (jelator 1 & Gelator 2 & $1 \cdot 2(1: 1 w 0 \%)$ \\
\hline J:thanol & $\mathrm{G}$ & $\mathrm{S}$ & $\mathrm{G}$ \\
\hline Acctonitrile & (j) & $\mathrm{S}$ & (j) \\
\hline n-Butanol & (j) & (ip & C \\
\hline Telrahydrofuran & $\mathrm{G}$ & 1 & I \\
\hline Chlorolorm & $\mathrm{S}$ & 1 & I \\
\hline Hexane & I & I & I \\
\hline Ethyl acetate & (j) & I & I \\
\hline Metheanol & $C$ & $S$ & C \\
\hline
\end{tabular}

"Gelator concentration: $5.0 \mathrm{w} \%$ \% $\%$ ol o $\mathrm{j}$ - stable gel at roum temperature, $\mathrm{S}=$ solution. $\mathrm{l}=$ insoluble, $\mathrm{C}=$ crystallize, $\mathrm{Gp}=$ partial $\mathrm{gel}$. 

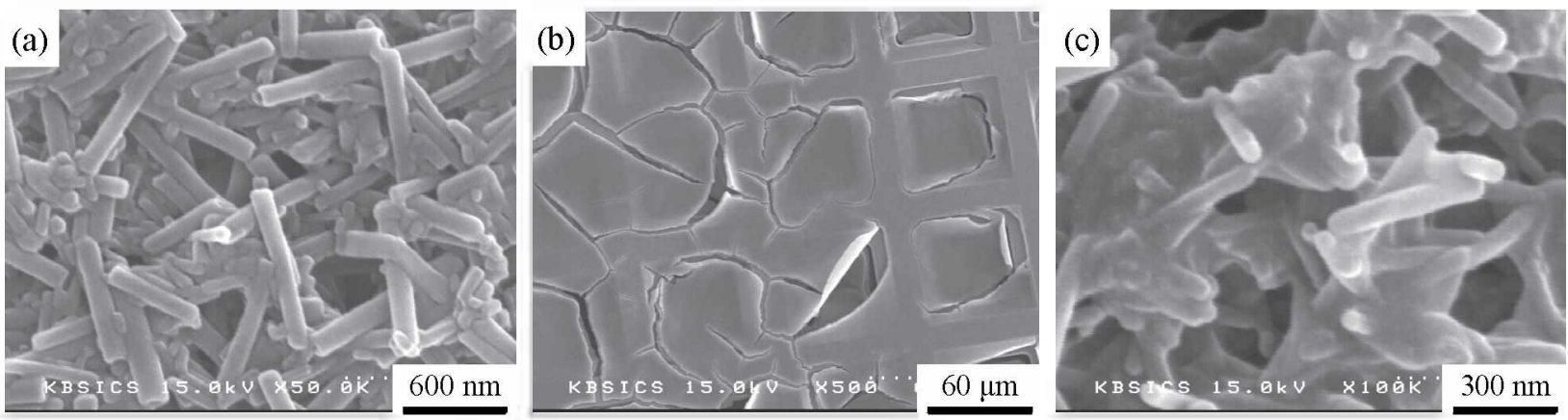

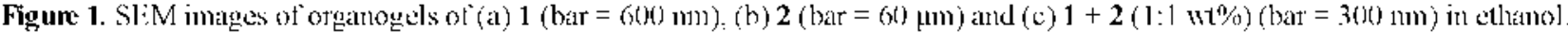
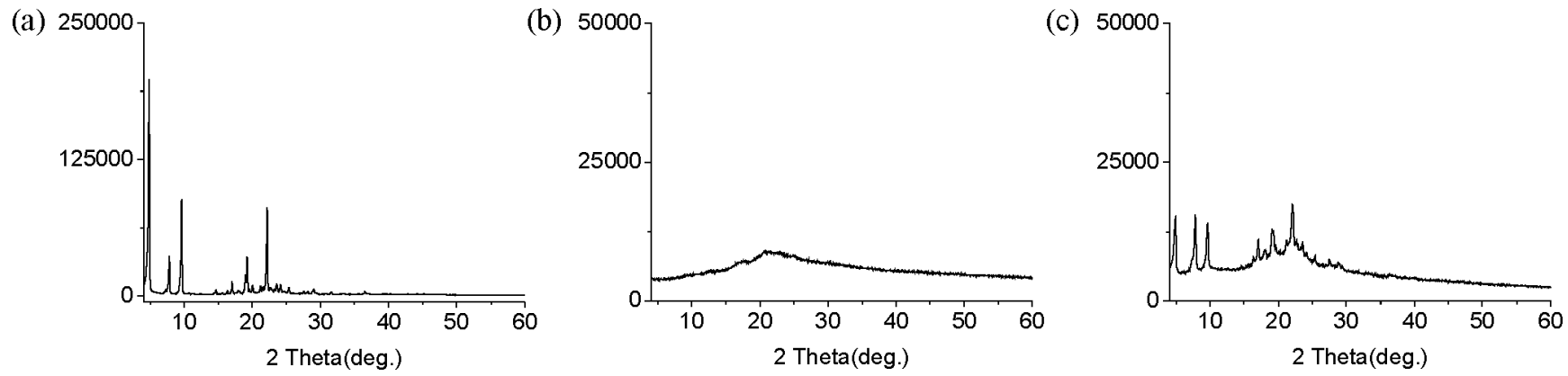

Figure 2. The XIRI) spectra of organogels of (a) 1 , (b) 2 and (c) $1+2(1: 1$ w1\%) in ethanol
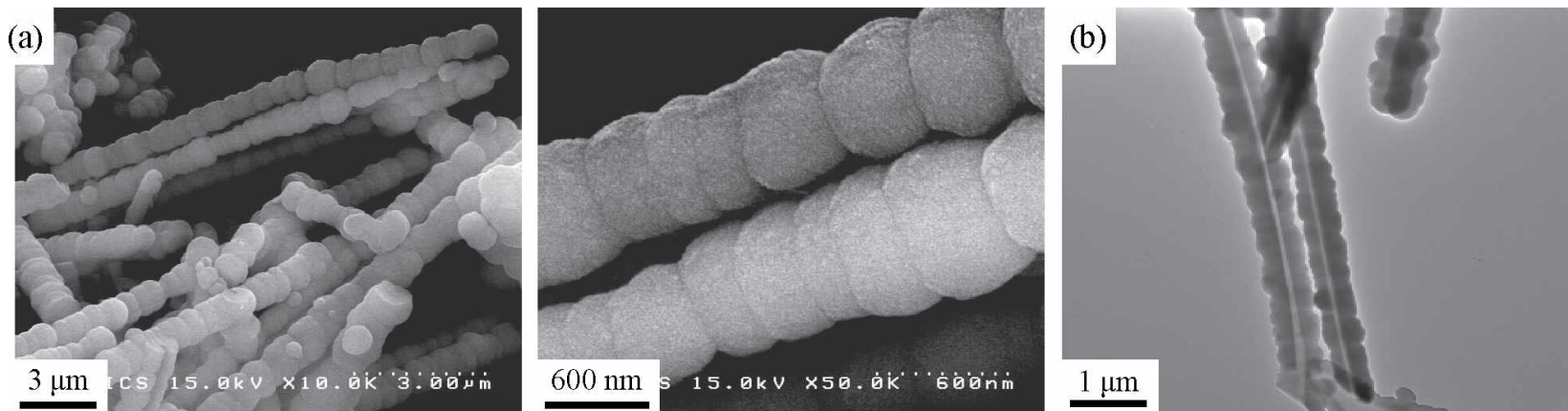

Figure 3. Sl:M (a) $($ har $=3 \mu \mathrm{m}$ and $600 \mathrm{~mm})$ and ll:M $(\mathrm{b})(\mathrm{bar}=1, \mathrm{~m})$ images of the silica obtained from the mixed gelator $(1+2,1: 1 \mathrm{w}(\%)$ in ethathol alter calcination.

Interestingly. 1he organogel prepared from the mixed gelator looks like that the rod-shiaped gel is relatively evenly covered by the non-shaped gel. These results indicale that the neutral and cationic gelators are not integrated in the single organogel structure. but they act independently in gelation.

The independent action of the neutral and cationic gelators of the nixed gelators in gelation can be supported by XRD spectrums. The XRD spectrums for the organogels of gelator 1. gelator 2 and the mixed gelator $(1+2.1: 1$ w $1 \%)$ obtained from chanol are shown in Figure 2. The organogel of gelator 1 shows a distinct cry stal unity (Figure $2 a$ ) while the organogel of gelator 2 does show amorphous pattem (Figure 2b). Interestingly. the XRD spectrum of the organogel of the mixed gelator is just the mixture of the two patterns (Figure 2c). These results indicate that the neutral and cationic gelators consisting of the mixed gelator do not act coorperatively in gelation. Consequently, 1wo different organogels seem to be formed independently from the neutral and cationic gelators. one organogel being covered by the other organogel. These results are exactly consistent with those observed by the SEM images of organogels.

In order to form silica. the sol-gel polycondensation of TEOS was carricd oul with gelator 1 , gelator 2 and the mixed gelator $(1+2.1: 1$ wt $\%)$ in ethanol. sespectively: wia the known procedure. The sol-gel polycondensation of TEOS with a single gelator as the neuiral gelator. 1 or the cationic gelator. 2 in ethanol was found to produce only silica particles. In contrast. the sol-gel polycondensation of TEOS with the mixed gelator in ethanol was found to produce silica nano tubes with an inner diameter of aboul $50 \sim 70 \mathrm{~mm}$ after calcination as shown by the SEM and TEM images in Figure 3. From these results. it is concluded that both of gelator 1 and gelator 2 are required for the formation of silica nano tubes by the sol-gel polycondensation of TEOS. but the rod-shaped organogel originated from the neutral gelator should be crenly covered by the cationic gelator for the formation of silica nano tubes. 
The same experiment was performed starting from (lR. $2 R$ )-(-)-diphenylethylenediamine and the results including the formation of the silica nanotubes were identical to those obtained with the use of ( $1 S .2 S)$-(-)-dipheny lethy lenediamine. Unfortunately. the helicity of the silica nano tubes was not clearly observed in either case.

In short in this study, we demonstrated that the neutral gelator determines the shape of organogel morphology, and the cationic gelator influences the polymerization of TEOS after covering the surface of the organogel originated from the neutral gelator using derivatives of $(1 S, 2 S)$-(-)-diphenylethylenediamine. From these results it is concluded that the neutral and cationic gelators play different roles in forming silica nano tubes.

\section{Experimental Section}

Synthesis of the neutral gelator 1 . Add $0.20 \mathrm{~g}(0.9+\mathrm{mmol})$ of (1S.2S)-(-)-diphenylethylenediamine. $5 \mathrm{~mL}$ of distilled dichloromethane and $0.30 \mathrm{~mL}(2.15 \mathrm{mmol})$ of triethylamine into a $50 \mathrm{~mL}$ one neck round bottom flask and stir well. Add $0.29 \mathrm{~mL}(2.11 \mathrm{mmol})$ of hexanoyl chloride slowly by using a dropping fumnel and stir the solution for 1 day. Use $2 \mathrm{~N}-\mathrm{HCl}$ (aq) and $2 \mathrm{~N}-\mathrm{NaOH}$ (aq) to extract organic layer from the water layer. Dry the organic layer with sodium sulfate then recrystallize to obtain $0.27 \mathrm{~g}$ (vield: $70.0 \%$ ) of the white solid compound:

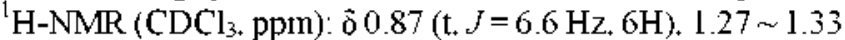
(m, 8H). $1.60(\mathrm{~m} .4 \mathrm{H}), 2.18$ (t. $J=7.2 \mathrm{~Hz}, 4 \mathrm{H}) .5 .24-5.27$ (dd $J=5.3 .2 .4 \mathrm{~Hz}, 2 \mathrm{H}), 6.81$ (s. $2 \mathrm{H}) .7 .09 \sim 7.17(\mathrm{~m} .10 \mathrm{H})$; ${ }^{13} \mathrm{C}-\mathrm{NMR}\left(\mathrm{CDCl}_{3}\right.$. ppm): ò $14.07 .22 .57,25.56 .31 .62,36.80$, $59.73,127.71,128.03,128.80 .138 .94 .174 .57$, FT-IR (KBr): $v_{\max } 3312,3064,3034,2954,2928,2859,1642,1540,1455$. $701 \mathrm{~cm}^{-1}:$ mp $224.0-224.5^{\circ} \mathrm{C}$ : Elemental analysis: $\mathrm{C}_{26} \mathrm{H}_{36} \mathrm{~N}_{2} \mathrm{O}_{2}$ (Mw: 395.27), calcd (\%): C. 76.43: H. 8.88: N. 6.86. Found: C. $76.53 ;$ H. $8.96 ;$ N. 6.96 .

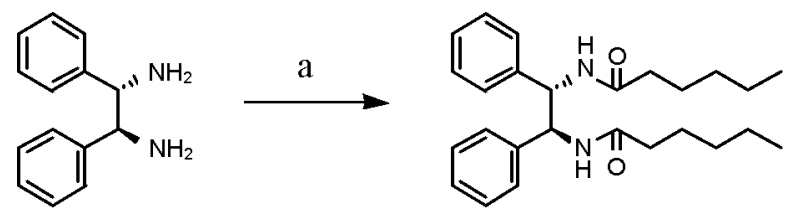

a. Hexanoyl chloride, $\mathrm{Et}_{3} \mathrm{~N}, \mathrm{CH}_{2} \mathrm{Cl}_{2}, \mathrm{rt}, 24 \mathrm{hrs}$

Synthesis of the cationic gelator 2. Add $0.20 \mathrm{~g}(0.94 \mathrm{mmol})$ of (1S,2S)-(-)-dipheny lethylenediamine, $5 \mathrm{~mL}$ of distilled dichloromethane. and $0.60 \mathrm{~mL}(4.30 \mathrm{mmol})$ of triethylamine into a 50 $\mathrm{mL}$ one neck round bottom flask and stir the solution at the room temperature for 30 minutes. Add $0.30 \mathrm{~mL}(2.2+\mathrm{mmol})$ of 5-bromovaleryl chloride slowly into the reaction solution by using a dropping funnel and stir at the room temperature for $\mathrm{I}$ day. Use $6 \mathrm{~N}-\mathrm{HCl}(\mathrm{aq})$ and $6 \mathrm{~N}-\mathrm{NaOH}(\mathrm{aq})$ to extract organic layer from the water layer. Dry the organic layer with sodium sulfate then remove the organic solvent at low pressure and recry stallize to obtain $0.25 \mathrm{~g}$ (yield: $50.5 \%$ ) of the white solid intermediated compound: ${ }^{\mathrm{H}} \mathrm{H}-\mathrm{NMR}\left(\mathrm{CDCl}_{3}, \mathrm{ppm}\right): \delta 1.73 \sim$ $1.89(\mathrm{~m} .8 \mathrm{H}) .2 .23(\mathrm{t} . J=7.5 \mathrm{~Hz}, 4 \mathrm{H}) .3 .39(\mathrm{t} J=6.3 \mathrm{~Hz}, 4 \mathrm{H})$, $5.24(\mathrm{dd} . J=5.3 .2 .4 \mathrm{~Hz} .2 \mathrm{H}), 6.68(\mathrm{~s} .2 \mathrm{H}), 7.09 \sim 7.21$ (m. 10
$\mathrm{H}):{ }^{13} \mathrm{C}-\mathrm{NMR}\left(\mathrm{CDCl}_{3}, \mathrm{ppn}\right): \delta 24.36 .32 .34 .33 .34 .35 .84 .59 .75$, 127.66. 128.11. 128.87, 138.86, 173.29: FT-IR (KBr): vax $3445,3290,3062,2936,1641,1538,1454,1376,1232,70 \mathrm{I}$ $\mathrm{cm}^{-1}$; $\mathrm{np} 142.2 \sim 142.7^{\circ} \mathrm{C}$. Elemental analysis: $\mathrm{C}_{24} \mathrm{H}_{3 i} \mathrm{Br}_{2} \mathrm{~N}_{2} \mathrm{O}_{2}$ (Mw: 536.07), calcd (\%): C. 53.55: H. 5.62: N. 5.20. Found: C, 53.63; H. 5.59; N, 5.32.

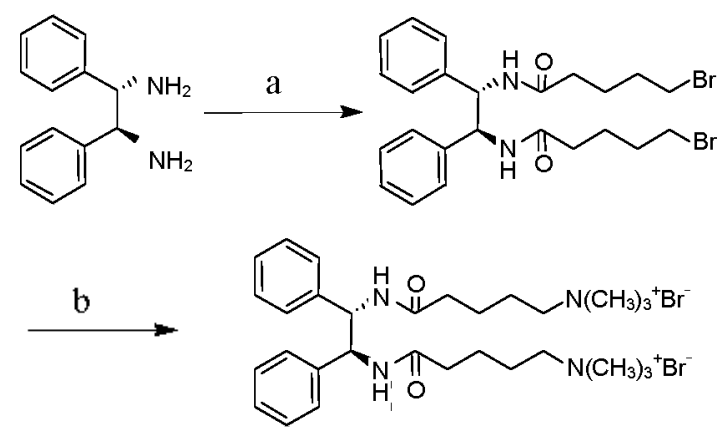

a. 5-Bromovalenyl chloride, Et $\mathrm{E}_{3} \mathrm{~N}, \mathrm{CH}_{2} \mathrm{Cl}_{2}, \mathrm{rt}, \mathrm{l}$ day

b. Trimethy lamine, THF: Ethanol (2:1), rt, 4 days

Add $0.27 \mathrm{~g}(0.49 \mathrm{mmol})$ of the sy nthesized internediate. 10 $\mathrm{mL}$ of the $2: 1$ mixture of THF and ethanol and $7 \mathrm{~mL}(75.32$ nimol) of trimethy lamine into a $5 \mathrm{~mL}$ one neck round bottom flask and stir at the room temperature for 4 days. Then remove the organic solvent at low pressure and recry stallize to obtain $0.27 \mathrm{~g}$ (yield: $70.5 \%$ ) of the grey solid compound: ${ }^{1} \mathrm{H}-\mathrm{NMR}$ $\left(\mathrm{CD}_{2} \mathrm{CN}, \mathrm{ppn}\right): \delta 1.51$ (m. $\left.8 \mathrm{H}\right) .2 .32(\mathrm{~m}, 4 \mathrm{H}), 3.00(\mathrm{~s} .18 \mathrm{H})$, $3.23 \sim 3.46(\mathrm{~m} .+\mathrm{H}) .5 .46(\mathrm{~d}, J=9.0 \mathrm{~Hz}, 2 \mathrm{H}), 7.25 \sim 7.28(\mathrm{~m}$, 2H). $7.3 \mathrm{I} \sim 7.37(\mathrm{~m}, 4 \mathrm{H}) .7 .56 \sim 7.60(\mathrm{~m}, 4 \mathrm{H}) .9 .06(\mathrm{~d}, J=9.0$ Hz. $2 \mathrm{H}$ ): ${ }^{12} \mathrm{C}-\mathrm{NMR}$ (CD $\mathrm{CD}$. ppm): ô 22.04. 22.34, 34.78, $52.37,57.79 .66 .12 .127 .30,127.38,128.20,139.80,173.54$ : FT-IR (KBr): $v_{\text {mek: }} 3430,3282,3062.3029 .2952$. 1640, 1537. $1489,1455,70 \mathrm{~cm}^{-1}: \operatorname{mp} 200.6 \sim 201.0^{\circ} \mathrm{C}$ : Elemental analysis: $\mathrm{C}_{3}\left(\mathrm{H}_{48} \mathrm{Br}_{2} \mathrm{~N}_{4} \mathrm{O}_{2}(\mathrm{Mw}: 654.2 \mathrm{l})\right.$. calcd (\%): C. 54.88: H. 7.37: N. 8.53. Found: C, 54.84; H. 7.21; N. 8.49.

Aclanowledgments. This work was supported by KBSI grant (T29508) to J. S. Jin and by MKE-RTI04-02-0I from the Regional Technology Innovation Progran of the Ministry of Knowledge and Economy. Korea. Jeong. This work was also supported by the National Core Research Center Program (No. R15-2006-022-03001-0) to M. H. Hyun and M. S. Shin.

\section{References}

1. Jung, J. H.: Amaike, M.: Shinkai. S. Chem. Commm. 2000. 2343.; Jung, T. H.; Lee, S. S.; Shinkai, S.; Iwaura, R.; Shimizu, T. Bull Korean Chem. Soc 2004. 25(1), 63.: Jung. S H.: Kim. E. J.; Lee, S. J.; Lee, C. G.; Lee, T. K.; Lee, S. S.; Jung, J. H. Bull. Konean Chem. Soc 2008, 29(8), 1630.

2. Ono, Y; Nakashima, K.; Sano, M.; Hojo, J.; Shinkai, S. Chemistru Letters 1999, 11 19.. Jung, J. W.: Ono, Y.: Saklrai, K.; Sato, M.; Shinkai, S. J. Am. Chem. Soc 2000, 122, 8648. Jurn, J. H.: Rim, I. A.; Lee, S. H.: Yoo, J. S.: Yoshida, K.: Shimizn, T.: Shirkai, S. Chent Eur: J. 2003, 9, 5307.

3. Hanabusa, K:: Yamada, M.: Kimura, M.: Shirai, H. Angew. Chem. Int. Ed. Engl. 1996, 35, 17.

4. Jung, J. W.; Ono, Y.; Hanabusa, K. Shirkai, S. J. An. Chent. Soc. 2000, 122, 5008 .: Kobayashi, S.: Hamasaki, N.: Suzuki, M.: Kimura, M.: Shirai H. Hanabusa $K$. J. Ant. Chent. Soc $\mathbf{2 0 0 2}, 12+, 6550$.

5. Jung, J. W.; Ono, Y; Shinkai, S. Chem. Em, J. 2000, 6, 4552. 